\title{
One Year In: Using a Mission-Driven Assessment Plan to Enact Change in an Academic Library Makerspace
}

\author{
Krystal Wyatt-Baxter and Amber Welch \\ University of Texas, USA
}

\section{Overview}

The Foundry is an interdisciplinary makerspace located in the Fine Arts Library (FAL) branch of the University of Texas Library (UTL) System. It had a soft opening in the fall of 2016. The space was created in partnership with the College of Fine Arts with a primary goal of making the creative process and creative practice accessible to any UT student, staff, or faculty member. To date, The Foundry is the only makerspace on campus that is open to any student, staff, or faculty member irrespective of departmental affiliation.

The approximately 4,000 square foot space provides access to mills, 3D printers, a laser cutter, a textiles area, a large format printer/cutter, a video wall, virtual reality (VR) headsets, a 3D scanner, and a recording studio. There are two full-time staff that support the space: a professional librarian and a media support technician. There are also a large group of student staff that provide coverage and assistance to patrons on the floor.

Between fall 2016 and fall 2017, The Foundry was primarily focused on developing workflows for how patrons would begin to utilize the space. This was in addition to allowing staff time to acclimate to and become proficient in the use of the equipment. During this time, an access and service model for the space began to take shape, as well as a mission statement, an assessment plan, and an onboarding plan for student staff. This time provided an opportunity for The Foundry to begin to design a standardized approach to teaching in the space, which would ensure consistent service provision and established learning goals on the equipment. This standardized approach includes an inclusive teaching and learning practices document, which is required reading for anyone teaching in the space.

The Foundry provides multiple points of entry for faculty, students, and staff. Faculty can request course integrated support for their students; students can walk in to use the space or can sign up for a certification through the campus learning management system, Canvas; and UT staff are welcome to use the space in the same way that students access services. Course integrated support does include providing exposure tours, but the preferred model of integration is one that aligns services with course learning goals and outcomes. This process includes a faculty consultation, during which Foundry staff develop a customized course support plan. Identifying learning outcomes, modifying assignment design and deadlines in partnership with faculty, and allocating blocks of time in the space for the class to work are all prioritized during the consultation. Faculty can also elect to use the space as a teaching space, in which they instruct their students on the equipment, or they can request that the Foundry librarian provide instructional support for the class. This support model is akin to the standard information literacy or research instruction session, with a primary focus on providing digital pedagogy support and advancing digital literacy efforts.

Student use of the space can generally be broken down into two primary paths. There are students that are completing assignments for courses, and there are independent learners that are interested in acquiring specific skill sets. In order to begin using The Foundry, students must first determine whether or not the specific piece of equipment that they want to use requires certification. Currently, all of the equipment in The Foundry requires certification except the $3 \mathrm{D}$ scanner, VR headsets, and the printer/cutter. A certification requires students to attend a 30-60 minute primer on the equipment. The focus of a certification is to acquaint patrons with the space, to provide them with an overview of safety protocol, to introduce them to the physical components of the equipment, and to provide them with a basic overview of the software that controls the equipment. Generally speaking, students are provided with the option to have hands-on exposure during a certification. 
Certifications are provided by student staff, classified, and professional staff. Employees from across UTL can teach in the space if they have the necessary skill set, and desire to contribute time to the space. Staff shares allow the space to be staffed by a variety of individuals with highly unique qualifications.

Between fall 2017 and fall 2018, having established stable workflows for patron engagement and having established a strong assessment plan, The Foundry began to shift its focus to campus outreach. The 2016-17 academic year provided Foundry staff with an opportunity to pilot course integrated support and certification provision. The following year, Foundry staff began to refine workflows and began targeting specific departments on campus as a result of 2016-17 assessment data. The goal of this outreach was to increase course-integrated use of the space. Much like learning labs and communal teaching spaces that are owned and managed by academic libraries, The Foundry is viewed as a learning lab, and Foundry staff believe the success of the space is dependent upon faculty designing assignments that require students to use the equipment.

While it was clear from the outset that assessing The Foundry would be essential, deciding how to do so raised more questions than answers during the planning stages of the space. Examples of how other academic libraries approached makerspace assessment were few and far between. Without best practices to rely on or benchmarks to compare against, assessment planning focused on practicalities and institutional needs. While the bulk of organized assessment planning for The Foundry takes place through a holistic plan that fits into an institutional assessment framework to be detailed below, supplemental measures, such as equipment usage tracking, aid in operational decision-making. While the official assessment plan is highly structured and written well in advance of its implementation, supplemental measures are often added and discarded on the fly. Using both levels of assessment allows for flexibility while keeping us on track with our mission and goals. This paper will share findings from the first full year of following a holistic plan and discuss how these findings are being used to gauge success and change service models as needed.

\section{Review of the Literature}

Literature on assessing makerspaces within higher education, particularly within academic libraries, is sparse. Most studies focus on either evaluation or assessment of a single aspect of a makerspace such as a particular service ${ }^{1}$ or aspect such as curricular integration. ${ }^{2} \mathrm{~A}$ few papers at the recent International Symposium on Academic Makerspaces focused on data collection, but none addressed assessment at a broader scale. ${ }^{3}$ This paper argues that approaching assessment in a holistically systematic manner, rather than simply collecting metrics on equipment usage and space headcounts, helps maintain focus on the intended purpose of a makerspace and has the added benefit of providing administrators with stories about the impact of the space.

\section{Developing the Foundry Assessment Plan}

Institutional assessment at the University of Texas takes place through a "Continuous Improvement Framework" through which campus operating units write and implement yearly assessment plans composed of aligned goals, outcomes, strategies for achieving the outcomes, assessment methods, and achievement targets. Around the time that The Foundry was being designed and built, the University of Texas Libraries began participating in this campus-wide outcomes-based institutional assessment framework. It naturally followed that the framework was used to guide initial assessment of the makerspace. As detailed in a previous publication, The Foundry staff started with a mission statement, then devised goals and outcomes that would support the unit's mission and align with UTL and institution-wide missions. ${ }^{4}$

The three broad goals of The Foundry are: (1) advance undergraduate, graduate, and faculty understanding of makerspace technology and the application of innovative production methods in educational and professional environments; (2) support interdisciplinary, constructivist learning and cooperation through strategic campus partnerships; and (3) develop and steward a safe, inclusive makerspace that represents the diverse population of faculty, students, and staff at UT. Outcomes that fall under these goals focus on (1.1) student creation; (1.2) exposure to makerspace technology; (1.3) integration of The Foundry into curriculum; (2.1) interdisciplinary constituency; and (3.1) learning environment. These goals and outcomes focus on 
mission-centric foundational and transformational aspects of The Foundry rather than on day-to-day operations, which helps to ensure that decisions are made with broad context and purpose in mind.

Outside of the holistic assessment plan, input and output measures such as equipment certification numbers are collected and analyzed as needed. Rather than a yearly cycle, these measures are gathered and analyzed in a more ad hoc manner and can be changed or discontinued as needs dictate.

\section{7-18 Foundry Assessment Plan Methods and Results}

\begin{tabular}{|c|c|c|c|c|}
\hline Goals & Outcomes & $\begin{array}{l}\text { Assessment } \\
\text { Methods }\end{array}$ & Targets & Results \\
\hline $\begin{array}{l}\text { Advance } \\
\text { undergraduate, } \\
\text { graduate, and } \\
\text { faculty } \\
\text { understanding of } \\
\text { makerspace } \\
\text { technology and the } \\
\text { application of } \\
\text { innovative } \\
\text { production methods } \\
\text { in educational and } \\
\text { professional } \\
\text { environments. }\end{array}$ & 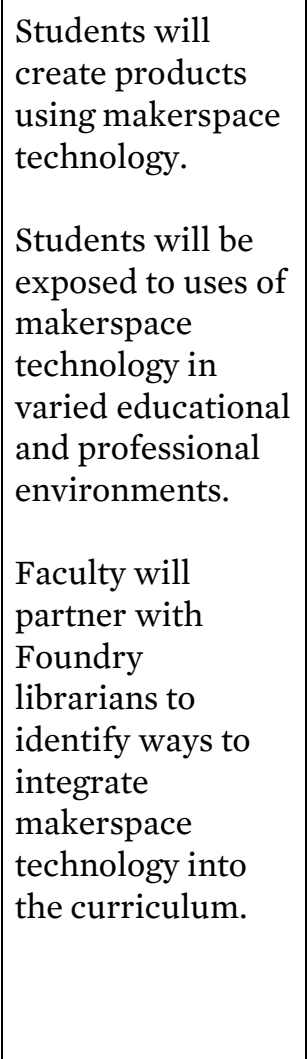 & $\begin{array}{l}\text { Focus group } \\
\text { surveys with } \\
\text { student staff, } \\
\text { Qualtrics } \\
\text { survey } \\
\text { administered } \\
\text { through } \\
\text { Canvas, and } \\
\text { Instagram } \\
\text { social media } \\
\text { contest. } \\
\\
\text { Qualtrics } \\
\text { survey } \\
\text { administered } \\
\text { through } \\
\text { Canvas and } \\
\text { faculty survey. } \\
\text { Course- } \\
\text { integrated } \\
\text { instruction } \\
\text { data and } \\
\text { faculty } \\
\text { surveys. }\end{array}$ & $\begin{array}{l}60 \% \text { of users achieve } \\
\text { goal of "using a piece of } \\
\text { equipment in The } \\
\text { Foundry to make } \\
\text { something" on Qualtrics } \\
\text { survey. } \\
\text { 60\% of faculty strongly } \\
\text { agree that exposure to } \\
\text { Foundry resources } \\
\text { expanded student } \\
\text { understanding of the } \\
\text { potential application of } \\
\text { makerspace tech in } \\
\text { their field/discipline. } \\
\\
5 \text { course-integrated } \\
\text { partnerships each } \\
\text { semester (tours, use of } \\
\text { technology, } \\
\text { presentation request). }\end{array}$ & $\begin{array}{l}\text { Achieved. } 88.9 \% \text { of } \\
\text { the } 27 \text { patrons that } \\
\text { answered this } \\
\text { question on the } \\
\text { patron survey } \\
\text { achieved their goal. } \\
\text { Not applicable. This } \\
\text { assessment method } \\
\text { was utilized once } \\
\text { during the spring } \\
\text { 2017 pilot. There } \\
\text { were no results } \\
\text { received to the } \\
\text { survey. This } \\
\text { assessment } \\
\text { method/strategy will } \\
\text { be eliminated from } \\
\text { the } 18-19 \text { plan. } \\
\text { Achieved. } 47 \text { course- } \\
\text { integrated } \\
\text { interactions in total. } \\
\text { FA2017 = } 8 \text { unique, } \\
\text { SP2018 = } 13 \text { unique. }\end{array}$ \\
\hline $\begin{array}{l}\text { Support } \\
\text { interdisciplinary, } \\
\text { constructivist } \\
\text { learning and } \\
\text { cooperation } \\
\text { through strategic } \\
\text { campus } \\
\text { partnerships. }\end{array}$ & $\begin{array}{l}\text { An } \\
\text { interdisciplinary } \\
\text { constituency will } \\
\text { utilize The } \\
\text { Foundry. There } \\
\text { will be broad } \\
\text { college and } \\
\text { departmental } \\
\text { representation. }\end{array}$ & $\begin{array}{l}\text { Course- } \\
\text { integrated } \\
\text { instruction } \\
\text { data, hiring } \\
\text { data, events } \\
\text { survey data, } \\
\text { workshop } \\
\text { attendee data, } \\
\text { EID data. }\end{array}$ & 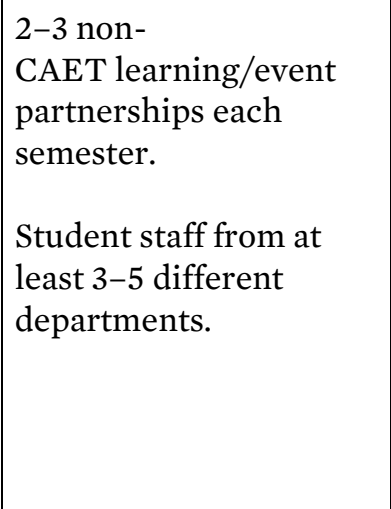 & $\begin{array}{l}\text { Achieved. } 16 \text { non- } \\
\text { AET partnerships. } \\
\text { Student staff from } \\
\text { College of Fine Arts } \\
\text { (6). } \\
\text { College of Liberal } \\
\text { Arts (2), School of } \\
\text { Architecture, School } \\
\text { of Engineering (3), } \\
\text { College of Natural } \\
\text { Sciences (2). }\end{array}$ \\
\hline
\end{tabular}




\begin{tabular}{|l|l|l|l|l|}
\hline Goals & Outcomes & $\begin{array}{l}\text { Assessment } \\
\text { Methods }\end{array}$ & Targets & Results \\
\hline $\begin{array}{l}\text { Develop and } \\
\text { steward a safe, } \\
\text { inclusive } \\
\text { makerspace that } \\
\text { represents the } \\
\text { diverse population } \\
\text { of faculty, students, } \\
\text { and staff at UT. }\end{array}$ & $\begin{array}{l}\text { Patrons will view } \\
\text { and experience } \\
\text { The Foundry as a } \\
\text { safe, inclusive } \\
\text { learning } \\
\text { environment. }\end{array}$ & $\begin{array}{l}\text { Focus group } \\
\text { surveys with } \\
\text { student staff; } \\
\text { Qualtrics } \\
\text { surveys } \\
\text { administered } \\
\text { through } \\
\text { Canvas course. }\end{array}$ & $\begin{array}{l}\text { 70\% of users feel } \\
\text { welcome in the space. } \\
60 \% \text { of users } \\
\text { satisfied/very satisfied } \\
\text { with service. }\end{array}$ & $\begin{array}{l}\text { Achieved. 60.8\% of } \\
\text { the 34 patrons that } \\
\text { answered the } \\
\text { question feel } \\
\text { "extremely } \\
\text { welcome, 21.6\% feel } \\
\text { "somewhat } \\
\text { welcome" in the } \\
\text { space. 73.5\% of the } \\
\text { 34 patrons that } \\
\text { responded to the } \\
\text { question felt } \\
\text { "extremely pleased" } \\
\text { with the quality of } \\
\text { service they received } \\
\text { during their last visit. }\end{array}$ \\
\hline
\end{tabular}

The Foundry Mission Statement: To provide access to an interdisciplinary, constructivist, inclusive learning space that encourages students, faculty, and staff to explore the practice of making.

\section{Data Collection and Methodology}

As a service of the UTL system, The Foundry serves and engages a wide range of patrons, primarily UT affiliates, but often prospective students and community visitors. The Foundry engages in continuous assessment throughout the academic year via a mixed methods assessment plan that includes patron surveys, student staff focus groups, and analysis of patron service usage and demographic data. Ethnic, gender, departmental, and other demographic data about the population that utilizes The Foundry is sourced from the campus learning management system, Canvas, once per year. That data is then joined with UT data and allows for a more specific demographic view of the patrons to emerge. The Foundry has an open enroll Canvas course which provides information about services offered and allows patrons to sign up for classes, receive event notifications, and read about the equipment in the space. The Foundry assumes that most patrons utilizing the space are also enrolled in the Canvas course. It is possible for a patron to use the service and not join the Canvas course, but this is fairly unlikely.

In addition to patron data, The Foundry gathers data from a patron survey, conducted once per year in spring; student staff focus groups, also conducted annually in spring; and from instruction and events data, which is maintained throughout the year. Qualtrics is utilized for patron surveys, focus groups are moderated by the head of assessment for UT Libraries. All quantitative and qualitative data is aggregated and anonymized prior to analysis.

Patron equipment certifications are another unit of assessment. These occur when a patron is certified to use a piece of equipment, such as a 3D printer. Monitoring certification levels ensures that the service is being utilized and demonstrates that ongoing investment in the service is warranted.

\section{Results}

As part of the Continuous Improvement Framework cycle, results from assessment methods included in the 2017-18 assessment plan were compiled and analyzed at the conclusion of the spring 2018 semester to determine whether outcomes were achieved. These findings were then used to inform the creation of actionable next steps intended to improve The Foundry. Assessment methods revealed that four out of five outcomes were achieved during the first assessment cycle, with the fifth outcome determined to need different methods in order to be assessed. 
The first three outcomes focused on ensuring that students and faculty were using The Foundry to enhance learning through both individual exploration and curricular integration. Two of three outcomes were achieved. The user survey revealed that almost $90 \%$ of respondents achieved the goal of "using a piece of equipment in The Foundry to make something," fulfilling outcome 1.1. Outcome 1.2 was unable to be assessed during this round due to lack of responses to the faculty survey. The third outcome under this goal was fully achieved, with 21 unique faculty partnerships recorded throughout the year.

The second goal and accompanying outcome focused on supporting interdisciplinary learning and was also achieved. Student data showed usage from a variety of disciplines, Foundry staff formed partnerships with faculty from outside the School of Design and Creative Technology, and student workers represented four different schools and colleges. Course-integrated use is slowly growing. The space attracts new academic partnerships each semester while retaining courses that previously used the space. Departmental use of the space is diverse, although there are some departments which utilize the space more heavily.

The final goal under the assessment plan was to develop and steward a safe, inclusive space that represents the diverse population on campus. This goal's accompanying outcome was also achieved. Data from 2017 to 2018 show that the Foundry is serving a diverse constituency. Usage by gender is largely evenly split, and the ethnicity of patrons using the space mimics campus level demographics, based on the 2017-2018 Statistical Handbook. ${ }^{5}$ Usage is steady and slowly growing, and events continue to draw in new patrons.

Although outcomes that were successfully assessed were all achieved, the Continuous Improvement Framework requires actionable next steps to be identified based on assessment findings. Next steps are intended to "close the loop" on the assessment cycle and are where the improvement portion of the framework comes into play. Since successfully achieving outcomes signaled that large programmatic changes were not needed, smaller improvements that do not tie directly to the plan outcomes were identified. The student staff focus group revealed that students felt the staff workroom was too messy and that some students were receiving relevant work information (such as information on policy changes) before others. These were simple fixes-the staff workroom has been cleaned and communication is now reinforced in person with student staff. Other action items included increasing outreach announcements through Canvas to try and raise the percentage of patrons who feel welcome in the space and purchasing a dress form for the textiles area as requested by patrons.

\section{Efficacy of methods}

Assessment methods used as part of the 2017-18 assessment plan were largely successful and resulted in data that provides a multifaceted view of the ways in which patrons engage with services provided by The Foundry. Faculty data presents an opportunity for improving data collection. When supporting faculty through course integrated partnerships, there are two reliable measures of their satisfaction: return visits/utilization of services year after year, and anecdotal feedback at the end of the semester, often gathered through in-person conversation or through an email exchange. It is difficult to capture this data in aggregate form, however, that does not detract from the validity or value it adds to the overall picture of services provided.

The current iteration of the assessment plan (2018-2019) includes the following modifications from the 2017-2018 version:

- Removed Target: " $60 \%$ of faculty strongly agree that exposure to Foundry resources expanded student understanding of the potential application of makerspace tech." Replaced with Target: "3 unique workshops offered each semester to any patron without charge."

- Assessment methods: added measures for workshop data, course-integrated tour data, and accompanying strategies (course-integrated tours, open tours available for anyone, workshops).

- Removed "Instagram social media contest" as an assessment method. 
Aside from faculty assessment data, there were largely no major challenges involved in deploying the assessment. The results are not only useful but inform almost every major operational decision that is made. More granular data is engaged with monthly, and population level data is engaged with twice per year on average. Those involved in deploying the plan believe the results are an accurate reflection of what is occurring in the space. Additional measures such as ILS data on equipment checkouts may be desired, but are not currently feasible. Limitations within the system make it prohibitively time-consuming to collect data that would likely yield useful information. In the future, collecting this data may be revisited.

An outcomes-based assessment plan is only one possible way to approach makerspace assessment. This kind of assessment prioritizes long-term planning over short-term adjustments, which has both positives and negatives. On the positive side, outcomes assessment ensures that staff keep larger goals in mind and annually ensures that current practices are aligned with the mission of the service or space. In the day-to-day tasks involved with running a service, it is easy to lose focus on values-based goals, such as inclusion, but outcomes assessment brings these initiatives to the forefront. On the other hand, yearly outcomes-based assessment plans do not prioritize short term ad hoc assessments that might yield useful information or the gathering of metrics that might prove useful down the road. Balanced assessment will likely include both kinds of practice, with yearly plans as well as time budgeted for assessment needs that arise spontaneously.

\section{Conclusion}

Looking ahead, The Foundry will continue to monitor population-specific demographic and space usage data. This is key to advancing the mission of The Foundry to reduce barriers to makerspace access, and to create and maintain a diverse and inclusive makerspace learning environment. Input and output measures will continue to be utilized as needed. We anticipate that operations will continue to improve as a result of holistically analyzing both day-to-day usage data, as well as population level data.

There is little in the field about broadly assessing makerspaces in academic libraries. We hope that this paper adds to the conversation by outlining the opportunities and challenges afforded by approaching makerspace assessment through an outcomes-based framework. As makerspaces continue to proliferate within academic libraries, we would like to see the literature evolve to discuss the use and efficacy of specific methods and metrics for values alignment and operational decision-making.

-Copyright 2019 Krystal Wyatt-Baxter and Amber Welch

\section{Endnotes}

1. Tara Radniecki, "Supporting 3D modeling in the academic library," Library Hi Tech 35, no. 2 (2017): 240250, https://doi.org/10.1108/LHT-11-2016-0121.

2. Martin Wallace, Gretchen Trkay, Katie Musick Peery, and Morgan Chivers, "Making Maker Literacies: Integrating Academic Library Makerspaces into the Undergraduate Curriculum" (Paper presentation, International Symposium on Academic Makerspaces, Cleveland, OH, September 2017).

3. Elden Schoop, Forrest Huang, Nathan Khuu, and Bjoern Hartmann, "MakerLens: What Sign-In, Reservation and Training Data Can (and Cannot) Tell You About Your Makerspace" (Paper presentation, International Symposium on Academic Makerspaces, Stanford, CA, August 2018); Ramy Imam, Leonard Ferron, and Amit S. Jariwala, "A Review of the Data Collection Methods Used at Higher Education Makerspaces" (Paper presentation, International Symposium on Academic Makerspaces, Stanford, CA, August 2018).

4. Amber N. Welch and Krystal Wyatt-Baxter, Beyond metrics: Connecting academic library makerspace assessment practices with organizational values," Library Hi Tech 36, no. 2 (2018): 306-318, https://doi.org/10.1108/LHT-08-2017-0181.

5. University of Texas 2017-2018 Statistical Handbook, https://utexas.app.box.com/v/SHB17-18Complete. 